\title{
artigo
}

\section{A pandemia do coronavírus e os impactos nas ações de saúde no primeiro semestre de 2020: revisão}

integrativa

The coronavirus pandemic and impacts on health actions in the first half of 2020: integrative review La pandemia del coronavirus e impactos en las acciones sanitarias en el primer semestre de 2020: revisión integrativa

\section{RESUMO}

O objetivo deste trabalho foi reunir evidências científicas e verificar manuais, guias, protocolos instrutivos. Método: Trata-se de uma revisão integrativa com seleção de 11 artigos disponiveis na PUBMED e nos periódicos internacionais publicados em janeiro até abril de 2020. Resultados: É possível inferir medidas essenciais para minimizar os impactos da pandemia, ao identificar um novo coronavírus gerou desafios para conter a transmissão comunitária diante dos recursos limitados da saúde pública, conhecer o perfil da gravidade do vírus, a desinfecção de ambientes, manter uma educação permanente e isolamento dos casos suspeitos. Conclusões: Com base nas evidências obtidas e a necessidade de informação à saúde pública, constatou-se a importância de informações a respeito do novo Coronavírus, além de conhecimentos mais visíveis da doença, contribuindo para uma educação continuada preventiva e ampla, reduzindo os impactos ocasionados e a sobrecarga das ações de saúde.

DESCRITORES: Coronavírus; COVID-19; Pandemia.

\section{ABSTRACT}

The objective of this work was to gather scientific evidence and verify manuals, guides, instructional protocols. Method: This is an integrative review with a selection of 11 articles available at PUBMED and in international journals published in January through April 2020. Results: It is possible to infer essential measures to minimize the impacts of the pandemic, when identifying a new coronavirus it generated challenges to contain the community transmission in the face of limited public health resources, to know the profile of the severity of the virus, to disinfect environments, to maintain an education and isolation of suspected cases. Conclusions: Based on the evidence obtained and the need for public health information, the importance of information about the new Coronavirus was found, in addition to more visible knowledge of the disease, contributing to a preventive and broad continuing education, reducing the impacts caused and the overload of health actions.

DESCRIPTORS: Coronavírus. COVID-19. Pandemic.

\section{RESUMEN}

El objetivo de este trabajo fue recolectar evidencia científica y verificar manuales, guías, protocolos instruccionales. Método: Esta es una revisión integradora con una selección de 11 artículos disponibles en PUBMED y en revistas internacionales publicadas de enero a abril de 2020. Resultados: Es posible inferir medidas esenciales para minimizar los impactos de la pandemia, al identificar un nuevo coronavirus generó desafíos para contener la transmisión comunitaria ante recursos limitados de salud pública, conocer el perfil de la severidad del virus, desinfectar ambientes, mantener una educación y aislamiento de casos sospechosos. Conclusiones: Con base en la evidencia obtenida y la necesidad de información en salud pública, se encontró la importancia de la información sobre el nuevo Coronavirus, además de un conocimiento más visible de la enfermedad, contribuyendo a una educación continua preventiva y amplia, reduciendo los impactos ocasionados. y la sobrecarga de acciones sanitarias.

DESCRIPTORES: Coronavirus; COVID-19 ; Pandemia.

RECEBIDO EM: 07/12/2021 APROVADO EM: 15/02/2021

\section{Flávia Pereira de Souza}

Bacharel em Enfermagem pela Faculdade Unida de Campinas - FacUNICAMPS, Goiânia - GO.

ORCID: 0000-0002-2244-3094 


\section{Marislei Espíndula Brasileiro}

Doutora em Ciências da Saúde -UFG, Doutora em Ciências da Religião- PUC-Go, Mestre em Enfermagem-UFMG , Goiânia - GO. ORCID: 0000-0003-3594-6384

\section{INTRODUÇÃO}

A Prevalência de um novo tipo de vírus de rápida extensão demográfica, que gera a pandemia nos remete à busca por evidências científicas. Em dezembro de 2019 a China notificou a Organização Mundial da Saúde (OMS) surtos de hospitalizações de indivíduos com diagnóstico de Pneumonia inexplicável ou SARS- $\mathrm{CoV} 2$, causadas pelo novo Coronavírus, em Wuhan, província de HUBEI, ocasionando um evento de emergência na Saúde Pública, em Março de $2020^{1}$.

Isolado em comum, quatro pacientes, onde a maioria era de trabalhadores das barracas no mercado de frutos do mar e animais silvestres: morcegos, pássaros, coelhos, sapos, tigres dentre outros, quando autoridades verificaram evidências de que o novo Coronavírus, nos humanos, era similar ao do morcego. Então, houve transmissão de fonte não humana, e, devido ao surto, foi fechado à comercialização o mercado, em $1^{\circ}$ de janeiro de 2020, para inspeção e saneamento ambiental, não tendo sido reaberto ${ }^{2}$.

De acordo com OMS e o Ministério da Saúde as informações estão sendo consolidadas, ajustadas, atualizadas conforme relatos baseados em evidências, diante do fato, houve a antecipação da data do calendário vacinal da Influenza à gripe $\mathrm{H} 1 \mathrm{~N} 1$, deste modo, como os profissionais de saúde irão classificar e identificar os casos suspeitos de H1N1 e SARS- CoV2, os grupos de riscos para cobertura vacinal são os mesmos?

Estudos analisados em diferentes tipos de materiais comprovam a persistência que a cepa do Coronavírus pode causar enquanto infeccioso em superfície inanimadas que dura entre duas horas até nove dias, nos garantindo a eficácia e importância da desinfecção de superfície com produtos biocidas, etanol de $62 \%$ à $71 \%$ e hipoclorito de sódio $0,1 \%$.

A virulência, alta transmissibilidade e situação de pandemia, além das escassas evidências remetem aos países solicitar à sociedade entrar em quarentena e isolamento social.
Colocar indivíduos e a massa populacional em restrição de movimento, quarentena ou isolamento social, como forma de propagação e prevenção do vírus, pode afetar psicologicamente indivíduos e profissionais da saúde, aonde a maioria apresentou comportamentos de frustração, medo, solidão, além dos casos relatados de suicídio, evidenciando que quanto maior o tempo de isolamento maior o impacto psicológico ${ }^{4}$.

A história conta da Saúde Pública no Brasil, que enfrenta fragilidades, principalmente no âmbito do SUS, devido à precariedade das unidades de saúde, em diversas regióes do Brasil, no que tange à infraestrutura, insumos e capacidade de enfrentamento desse novo vírus. Nesse sentido há que se questionar: quais as informações científicas reunidas até o momento, a respeito do $\mathrm{CO}$ VID-19 e seu impacto na saúde pública? Há protocolos e POP's sobre a assistência da enfermagem para esses casos?

Este estudo tem como objetivo identificar evidências científicas reunidas, até o momento, a respeito da COVID-19, verificar manuais, guias, protocolos instrutivos e seus impactos na Saúde Pública.

\section{MÉTODO}

O presente estudo refere-se à Revisão Integrativa da Literatura, de acordo com Mendes, Silveira e Galvão (2008) é qualificado em evidências de estudos já existentes, desenvolvidos através de metodologias, disponíveis em diferentes fontes, ofertando aos pesquisadores a síntese e extração dos resultados sem afetar a referência dos estudos abrangidos e utilizados. Esta pesquisa ocorreu no período anual entre janeiro e abril de 2020.

Revisão esta desenvolvida por meio de seis etapas, sendo elas:

Primeira Etapa: Designação do tema e escolha da tese ou indagação de pesquisa para elaboração da revisão integrativa.

A identificação do tema A Pandemia do Coronavírus e os impactos nas açôes de saúde no primeiro semestre de 2020, manifestou-se devido a necessidade de informações relevantes, questionada a urgência de estudos com relação ao conhecimento e conduta do enfermeiro diante deste paciente, e para verificar o manejo clínico de acordo com as pesquisas fundamentadas a fim de obter assistência de qualidade humanizada para o paciente.

Segunda Etapa: Definição de medidas para a seleção dos estudos de amostragem ou busca na literatura.

A pesquisa dos artigos foi realizada na fonte da biblioteca digital da PUBMED nos periódicos da Jama Network - revista médica - publicada pela American Medical Association; The Journal Hospital infection, no jornal oficial da Sociedade de Infecção Hospitalar; The Lancet (Elsevier) - revista científica de Medicina - Reino Unido; New England Journal of Medicine (N ENGL J.MED) da Sociedade Médica de Massachusetts; Organização Mundial da Saúde (OMS); Ministério da Saúde do Brasil (MS); Conselho Federal de Enfermagem do Brasil (COFEN). Com relação ao levantamento dos artigos, os descritores de saúde (Decs) utilizados foram o Coronavírus, COVID-19, e, pandemia. Os Decs escolhidos têm relação direta com o tema proposto e são reconhecidos como descritores de ciência. Os critérios de inclusão para o presente estudo foram artigos publicados no período entre janeiro e a abril de 2020, disponíveis nos idiomas Português e Inglês, traduzidos para o presente estudo, nas fontes de pesquisas já referidas.

Terceira Etapa: Seleção do conteúdo a ser utilizado - artigos/categorização - no estudo.

As informações alcançadas foram selecionadas segundo tais critérios de inclusão: título do artigo, ano, local, periódico/revista, metodologia dos artigos, resultados dos estudos.

Quarta Etapa: Avaliação dos estudos incluídos na Revisão Integrativa.

Os estudos foram avaliados primeiramente por seus títulos, resumos, objetivos, resultados alcançados, obtendo, assim, uma resposta satisfatória e conclusiva.

Quinta Etapa: Interpretação dos resultados. 


\section{artigo}

Souza, F.P.; Brasileiro, M.E.

A pandemia do coronavírus e os impactos nas ações de saúde no primeiro semestre de 2020: revisão integrativa

Os resultados dos artigos foram obtidos através da leitura precisa, interpretação concreta, para que os dados fossem avaliados e agrupados.

Sexta etapa: Síntese do conhecimento evidenciado e analisado nos artigos pesquisados e apresentação da Revisão Integrativa.

As informações obtidas serão demonstradas nos quadros a seguir, e discutidas entre si. Foram demonstradas em dois quadros (1 e 2), nos quais a discussão dos dados foi realizada por divisão das informações, de modo que permitisse melhor entendimento e interpretação. Foram ordenados em número, referência e resultados. Quanto ao Quadro 2, foram ordenados por referência e protagonismo do enfermeiro, conforme relatos dos artigos estudados.

Quadro das evidências científicas.

\section{Tabela 01 - Classificação dos níveis de evidências}

$\begin{array}{ccc}\text { FORÇA } & \text { NÍVEL } & \text { PRÁTICA BASEADA EM EVIDÊNCIAS } \\ \text { Forte } & 1 & 1 \text { Metanálise de múltiplos estudos controlados } \\ \text { Forte/moderada } & 2 & 2 \text { Estudo experimental individual }\end{array}$

$\begin{array}{lcr}\text { Forte/moderada } & 3 & \begin{array}{r}\text { Estudo quase experimental como grupo único não rando- } \\ \text { mizados, controlados, com pré e pós testes, ou estado tipo } \\ \text { caso controle }\end{array} \\ \text { Moderada/Fraca } & 4 & \begin{array}{r}4 \text { Estudo não experimental, descritivo correlacional, qualita- } \\ \text { tivos ou estudo de caso }\end{array} \\ \text { Moderada/Fraca } & 5 & \begin{array}{r}5 \text { Relatório de caso ou dados obtidos sistematicamente, de } \\ \text { qualidade verificável, ou dados de programas de avaliação }\end{array} \\ \text { Moderada/Fraca } & 6 & 6 \text { Opinião de autoridades, comitês, órgãos legais } \\ \text { Fonte: BRASILEIRO,2017 } & & \end{array}$

Gráfico 01 - Eficácia da quarentena de isolamento social na contenção da epidemia COVID-19.

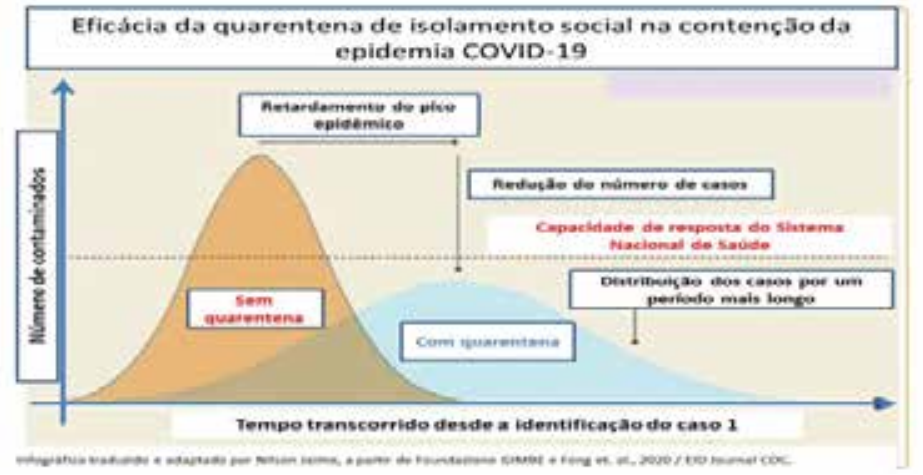

Fonte: OMS (Organização Mundial da Saúde), Coronavirus Resource Center da Johns Hopkins University, Junk Charts, The Economist, CDC (Centers for Disease Control and Prevention) e The New York Times - adaptado
${ }^{11} \mathrm{Li}$ et al. (2020) evidenciou 425 casos de pneumonia com causa inexplicável, em Wuhan, na China. Foram identificados, no mês de dezembro de 2019, em indivíduos do sexo masculino, idade média 59 anos, alta propagação na comunidade. Com objetivo de identificar um novo patógeno, os fatos direcionam à necessidade de implantar meios na prevenção de abordagem e orientação com medidas educativas em saúde. $\mathrm{O}$ estudo analisado fundamenta que houve contato direto ou indireto de transmissão de forma comunitária.

Ao identificar um novo patógeno de Coronavírus, que causa pneumonia grave, relacionado à (SARS-CoV-2) síndrome respiratória aguda grave, infere que ainda não existe vacina eficaz para esta nova patologia (RALPH et al., 2020) ${ }^{2}$.

Desde modo, a enfermagem necessita implementar medidas e estratégias de isolamento do contato respiratório, manejo com o paciente, introduzir a educação continuada, avaliar a rotina de cada instituição, visto que foi descrito e isolado o genoma do vírus SARS-CoV-2 que ocasiona a pneumonia, posteriormente denominada a doença de COVID-195.

Conter a propagação do COVID-19 garante o controle do surto, desde que em tempo hábil, onde se deve utilizar e intensificar os cuidados com a saúde de isolamento para facilitar o tratamento, de acordo com sinais e sintomas, com maior eficácia, na identificação na triagem de classificação de risco, sem atrasos no isolamento dos casos suspeitos ${ }^{6}$.

A enfermagem exige atualização de estudos baseados em evidências, visto que um novo vírus ocasiona a pandemia de calamidade pública. Ainda, sabe-se que os mecanismos de ação, e a característica patológica do Coronavírus são altamente mutáveis, e o tratamento é pouco evidenciado 7 .

Diante da pandemia vários países solicitaram à sociedade que entrasse em quarentena, uma forma de isolamento social. Essa estratégia é uma maneira de conter o vírus e a exposição de indivíduos não contaminados com grande eficácia como visto no Gráfico 1. Sendo assim está evidenciado que a mudança ocasiona psicologicamente impactos no comportamento dos indivíduos tais como medo, frustração, solidão, rela- 
tos de suicídio. E enquanto profissionais da saúde urge-nos apoiar estes indivíduos de forma humanizada ${ }^{3}$.

A seguir, o gráfico ilustrativo da eficácia da quarentena.

\section{RESULTADOS}

Os estudos abordados denotam a necessidade de implementar nova rotina, tanto na comunidade quanto nas unidades de saúde. A capacitação dos profissionais da saúde, sua atualização sobre as características da infecção do novo Coronavírus, e, assim identificar o perfil da gravidade como forma de contribuição para o melhor manejo e controle dos casos ${ }^{8}$.

Desta forma o trabalho observou surgimento de medicações viáveis para minimizar a evolução da doença no or- ganismo - visto no artigo anteriormente apresentado e que revela a cloroquina (CQ) e hidroxicloroquina (HCQ), ainda que não haja medicação específica, nem vacina até o presente momento (LIU et al., 2020). De acordo com Ministério da Saúde existem formas de tratamento para cuidados clínicos a pacientes com a COVID-19, que estavam em ventilação mecânica, receberam metilprednisolona e antivirais e, após transfusão de plasma, tiveram resultados significativos?.

Ainda são necessários maiores estudos para obter uma declaração definitiva a respeito das ocorrências. Segundo avaliação de gestante com 34 semanas de gestação, suspeita de ter contraído a SARS-CoV-2, e que teve o neonato de cesariana, nascido sem sintomas, mesmo assim encaminhado ao isolamento, sem contato com a mãe. $\mathrm{O}$ exame do recém-nascido para COVID-19 deu negativo, lembrando que o seu IgG e IgM eram elevados, mesmo o leite materno constando negativo ${ }^{10}$.

Frente às evidências científicas elencadas pelos estudos acima é possível inferir que medidas essenciais devem ser tomadas para minimizar os impactos da pandemia provocada pelo Coronavírus.

\section{CONCLUSÃO}

Conclui-se com base nas evidências obtidas, a necessidade de divulgar e informar a Saúde Pública a respeito do novo Coronavírus. Contribuir para os profissionais de saúde com atualizações para uma educação continuada preventiva e ampla, reduzindo os impactos ocasionados e a sobrecarga nas ações de saúde. -

\section{REFERÊNCIAS}

1. Brasileiro ME: A Enfermagem Quântica e o Paradigma das Evidências Científicas. Revista Científica Multidisciplinar Núcleo do Conhecimento. 2017; 06; 135-145. Disponível em: <www.revistanucleodoconhecimento.com.br//saude/enfermagem-quantica>. Acesso em: 11 jan. 2021.

2. Ralph R, et al.: 2019-nCov (Wuhan vírus), à novel Coronavirus: human-to-human transmission, travel-related cases and vaccine readiness.J. Infect. Dev. Ctries., Canada 2020; acesso 23 de Abril de 2020; 14; 3-17. Disponível em: https://doi.10.3855/jidc.12425.

3. Brooks S, et al.: The psychocological impact of quarantine and how to reduce it: rapid review of the evidence. Department of Psychological Medicine, King's College London, United Kingdom ,February 26, 2020; acesso 21 de Março de 2020. Disponível em: https://doi.org/10.1016/S0140-6736(20)30460-8.

4. Kampf G, et al.: Persistence of coronaviruses on inamimate surface and their inactivation with biocidal agents. The Of Jornal Hospital Infection, Germany February 2020; acesso 18 de Março de 2020; 104; 246-251. Disponivel em: https://doi.org/10.1016/.

5. Kim J, et al.: Identification of Coronavirus Isolated from à Patient in Korea with COVID-19. Osong Public Health and Research Perspectives, Korea, February de 2020; acesso 28 de Março de 2020; 11; 3. Disponível em https//doi.10.24171/j.phrp.2020.

6. Hellewell J, et al.: Feasibility of controlling COVID-19 outbreaks by isolation of case and contacts. Lancet Glob. Health., London, United Kingdom, February 2020; acesso 18 de Abril de 2020 .Disponivel em: https://doi.org/10.1016/s2214-109x(20)30074-7.

7. Xu Z, et al.: Pathological findings of COVID-19 associated with acute respiratory distress syndrome. The Lancet Respiratory Medicine, Beijing, China,Elsevier February 2020; acesso 21 de Abril de 2020. Disponivel em: https://doi.10.1016/.
8. Wu P, et al.: Real-time tentative assessment of the epidemiological characteristics of novel coronavirus infections in Wuhan, China. Euro Surveill, Hong Kong ,January 2020; acesso 21 de Abril de 2020; 25. Disponível em: https://doi.org/10.2807/15607917.ES.2020.25.3.2000044.

9. Shen C, et al.: Treatment of 5 critically patients with COVID-19 with convalescent plasma.J.A.M.A ,China March 27, 2020 ; acesso 21 de Maio de 2020. Disponível em: https:/doi10.1001/Jama.2020.4783.

10. Dong $L$, etal.: Possible vertical transmission of SARS-CoV-2 froman Infected mother to her newborn. J.A.M.A., China March 26, 2020; acesso 18 de Abril de 2020. Disponível em: https:doi:10.101/20204621.

11. Li Q, et al.: Early transmission dynamics in Wuhan, China of novel coronavirus-infected pneumonia. N Engl J. Med,Massachusetts, January 2020; acesso 18 de Março de 2020. Disponivel em: https//doi.10.1056/NEJoa20011316.

12. Liu J, et al.: Hydroxychloroquine, a less toxic derivative of chloroquine, is effective in inhibiting SARS-CoV- 2 infection in vitro. Cell Discov, Beijing, China 2020; acesso 21 de Março de 2020; 6. Disponivel em: https://doi.org/10.1038/s41421-020-0156-0.

13. Mendes KDS, Silveira RCCP, Galvão CM: Revisão integrativa: Método de pesquisa para incorporação de evidências na saúde e na enfermagem. Texto e Contexto Enfermagem,2008 .Universidade de Santa Catarina. Acesso 25 de março de 2020; 17; 758754. Disponivel em: http://www.scielo.br/pdf/tce/v17n4/18.pdf.

14. OMS - Organização Mundial da Saúde. Coronavirus Resource Center da Johns Hopkins University, Junk Charts, The Economist, CDC (Centers for Disease Control and Prevention) e The New York Times - adaptado. Acesso 06 de maio de 2020. Disponivel em: https://www.youtrading.com/2020/03/12/ um-grafico-explica-a-pandemia/. 